\title{
Effect of different insecticides on adult emergence of Trichogramma chilonis (Ishii)
}

\section{BHARGAVI}

Department of Agricultural Entomology, College of Agriculture, DAPOLI (M.S.) INDIA

\section{ARITCLE INFO \\ Received : 24.12 .2016 \\ Revised : 06.03 .2017 \\ Accepted : 12.03 .2017}

\section{KEY WORDS :}

Adult emergence, Oxydemeton methyl, Cypermethrin, Dimethoate, Malathion, Trichogramma chilonis

Email : baachi.agbsc@gmail.com

\begin{abstract}
The present investigations were undertaken on laboratory studies of Trichogramma chilonis (Ishii) during the year 2013-2014 in the Bio-control laboratory, Department of Agricultural Entomology, College of Agriculture, Dapoli (Maharashtra).The results of effect of different insecticides on adult emergence of $T$. chilonis revealed that insecticides viz., oxydemeton methyl can be safely used in the field after release of T. chilonis. However, insecticides viz., cypermethrin, dimethoate, indoxacarb and emamectin benzoate can be wisely used in the field 4-5 days after release of T. chilonis, while malathion and dichlorvos should strictly be retrained from their use as they reduce the per cent adult emergence.
\end{abstract}

How to view point the article : Bhargavi, M. (2017). Effect of different insecticides on adult emergence of Trichogramma chilonis (Ishii). Internat. J. Plant Protec., 10(1) : 79-82, DOI : 10.15740/HAS/IJPP/10.1/79-82. 